\title{
North American Brain Tumor Consortium
}

National Cancer Institute

\section{Source}

National Cancer Institute. North American Brain Tumor Consortium. NCI Thesaurus. Code C37995.

Dedicated to the development and conduct of innovative clinical trials that will ultimately result in a cure for patients with malignant brain tumors. Their goals are 1) to discover new and effective therapies for the treatment of patients with brain tumors, including anti-angiogenesis drugs, differentiating agents, anti-invasive medications, and new molecular agents such as gene therapy; 2) to develop innovative combination strategies to enhance the therapeutic effects of chemotherapy and radiation treatments; and 3) to develop and fund translational research opportunities that will bring exciting new agents and strategies from the laboratory to the clinical setting. 